\title{
Building and Running General Equilibrium Models in EViews
}

\author{
B. Essama-Nssah \\ Poverty Reduction Group (PRMPR) \\ The World Bank \\ Washington. D.C.
}

\begin{abstract}
A crucial step in policy analysis involves computing consequences of policy actions. This paper shows how to implement numerically a general equilibrium model in EViews. Computable general equilibrium models are now commonly used in both developed and developing countries to assess the impact of external shocks or economic policies on the structure of the economy or the distribution of welfare. The current version of EViews offers a set of tools for building and solving simulation models in general. The same tools make it possible to conduct policy analysis within a general equilibrium framework. Based on the generalized Salter-Swan framework and macroeconomic data for Indonesia, the paper demonstrates how to process a social accounting matrix (SAM), specify and calibrate the model, and run simulations. The results replicate welfare and structural effects of shocks and policies consistent with the underlying conceptual framework. They also reveal the key role played by structural parameters, such as the elasticity of export transformation and that of import substitution, in determining the extent of structural adjustment to shocks, and the relevance of the policy response.
\end{abstract}

JEL Classification: C63, C68

World Bank Policy Research Working Paper 3197, January 2004

The Policy Research Working Paper Series disseminates the findings of work in progress to encourage the exchange of ideas about development issues. An objective of the series is to get the findings out quickly, even if the presentations are less than fully polished. The papers carry the names of the authors and should be cited accordingly. The findings, interpretations, and conclusions expressed in this paper are entirely those of the authors. They do not necessarily represent the view of the World Bank, its Executive Directors, or the countries they represent. Policy Research Working Papers are available online at http://econ.worldbank.org. 


\section{Introduction}

This paper explains how to set up and run a general equilibrium model for policy analysis using EViews ${ }^{1}$ as a computing platform. A public policy is a collective choice made either by the whole society for itself (using a voting mechanism) or for society by its elected representatives (Quade 1982:3). The quality of such a choice hinges critically on the nature of the underlying process. In a broader sense, the process involves four phases: (i) understanding the relevant issues; (ii) searching for feasible courses of action; (iii) adopting and implementing the most desirable ones; and (iv) monitoring and evaluating the consequences to determine whether intended outcomes are being attained in a desirable manner.

The search for feasible actions and the identification of the most desirable among the feasible are necessarily constrained by the analytical input. The reliability of such input is in turn determined by the reliability of the underlying view of the world or organizing framework, and the information set to which this framework applies. There are at least two approaches in policy-making. The normative approach involves essentially: (i) the specification of the workings of society and instruments of policy intervention; (ii) the selection of an evaluation criterion; and (iii) the computation of values of the instruments that will either maximize the criterion or lead to some improvement of performance as measured by the chosen criterion. The standard way to proceed under this approach is to maximize a social welfare function subject to the economy's resource and technology constraints as if the government could set activities and make all decisions for all economic agents. The outcome of such a process is supposed to be implemented by a set of competitive and complete markets subject to the prevailing ownership of resources (Dixit 1996: 4-5).

The positive approach, as expressed in the public choice or the contractarian framework is based on the distinction between the policy regime (or constitution) that governs the whole policy-making process and individual policy acts (Dixit 1996:13). This approach, which emphasizes the political economy of policy-making, generally

\footnotetext{
${ }^{1}$ EViews stands for Econometric Views, a Windows version of a software designed by Quantitative Micro Software (QMS) primarily for time-series analysis and for the conduct of general econometric analysis. This paper is based on version 4.1 (November 4, 2003). The language is based on the fundamental concept of object, a collection of related information and operations.
} 
relies on a game theoretic approach to predict how various actors would behave in response to perceived policy-induced payoffs.

Whether one adopts the positive or the normative approach to policy-making, the ability to compute the consequences of policies is of crucial importance. In this context, simulation models can help a great deal. In particular, computable general equilibrium (CGE) models are now commonly used both in developed and developing countries as a means for evaluating the impact of external shocks or of economic policy on the structure of the economy or the distribution of welfare. Devarajan and Robinson (2002) review the use of CGE models to influence public policy. They note that such models have contributed to policy debates on structural adjustment, international trade ${ }^{2}$, public finance, agriculture, energy and environment. This widespread use is due not only to rapid development in computing technology ${ }^{3}$, but also to the fact that general equilibrium models offer the possibility to study differential impacts across sectors of production and across socioeconomic groups, and the opportunity to account for interaction among different sectors and economic agents. In addition, the approach provides a consistent framework for the assessment of tradeoffs associated with different policies.

A model is a logical picture of a phenomenon. Analytically, it is represented by a set of one or more equations that jointly describe the relationship between a group of variables. Typically, equations that enter an EViews model may be simple identities or derived from various estimation procedures. The model object combines these equations into a single entity which may be used to create deterministic or stochastic joint forecasts or simulations of all the variables in the model.

The variables of the model are divided into two basic categories. The first category, known as exogenous variables, consists of those variables that are determined

\footnotetext{
${ }^{2}$ In particular, the two authors provide an account of the use of CGE models in the North American Free Trade Agreement (NAFTA) debate to study issues such as: (1) the distribution of costs and benefits among the three partners (Canada, Mexico and the U.S.A.); (2) the impact of the agreement on employment and wages in the U.S.; (3) the impact of NAFTA on the migration between Mexico and the U.S.; (4) impact of NAFTA on agriculture, automobile industry and textiles in the three countries; and (5) impact of NAFTA on the bilateral trade balance between Mexico and the U.S.

${ }^{3}$ Robinson, Yunez-Naude, Hinojosa-Ojeda, Lewis and Devarajan (1999) describe how to implement multisectoral CGE models in GAMS (General Algebraic Modeling System), a high-level modeling system for mathematical programming problems. The system was developed by a team led by Alex Meeraus. Simple general equilibrium modeling in Excel is presented by Devarajan, Go, Lewis, Robinson and Sinko (1997).
} 
outside the model. Variables that are determined inside the model are known as endogenous variables. They constitute the second category. EViews can handle only square systems to the extent that each equation in the model must have a unique endogenous variable assigned to it. Thus, any variable that is not assigned as an endogenous variable is considered exogenous to the model. This is a crucial fact that must be borne in mind. Thus, for a model to have a unique solution, it is desirable that the number of independent equations be equal to the number of endogenous variables.

Model specification uses either inline or linked equations. An inline equation shows the specification of the equation as text within the model. A linked equation imports its specification from an external EViews object such as an estimation object. Equations may also be distinguished according to whether they are stochastic or identities. Stochastic equations are expected to hold only up to random error. Typically, they result from statistical estimation procedures. There exists a special category of exogenous variables associated with stochastic equations. These are known as add factors because they are used to shift the results of a stochastic equation to provide a better fit to historical data or to fine-tune the forecasting results of the model. Identities are expected to hold exactly. They usually represent accounting relationships among variables.

The solution of a model provides a set of values for endogenous variables that are consistent with a given set of exogenous variables. Here, consistency means that the equations of the model are satisfied within some numerical tolerance. The solution process requires that we first associate data with each variable in the model by binding each of the model variables to a series in the workfile. This will often entail a modification of the name of the variable to generate the name of the series that will contain the values associated with a particular solution. For instance, for an endogenous variable called $\mathbf{y}$ in the model, EViews may assign solution values to a series in the workfile called y_o, depending on the aliasing rule. Aliasing is a name mapping procedure that allows the variables in the model to be mapped into different sets of workfile series without having to alter the equations of the model.

When applied to endogenous variables, aliasing protects historical data from being overwritten. For models that contain lagged endogenous variables, aliasing allows 
one to bind the lagged variables either to the actual historical data (in the case of a static forecast), or to the values solved for in the previous periods (in the case of a dynamic forecast). In the case of exogenous variables, aliasing is applied when using model scenarios. A scenario represents a set of assumptions concerning variables that are determined outside the model (i.e. exogenous variables). In a scenario, one can change the path of an exogenous variable by overriding the variable. When a variable is overridden, the values for that variable will be fetched from a workfile series specific to that scenario. The name of the series is formed by adding a suffix associated with the scenario to the variable name. The same suffix will be used when storing the solutions of the model for the scenario.

The outline of the paper is as follows. Section 2 is an introduction to simple general equilibrium modeling using the generalized Salter-Swan model (also known as the 1-2-3 model $^{4}$ ) of an open economy. We consider two variants of this framework. The first is a stripped down version with three representative agents: a producer, a consumer and the rest of the world. Following a description of the basic structure of this variant, we demonstrate its numerical implementation using a simple example from de Melo and Robinson (1989). In particular, we show how to analyze welfare and structural implications of external shocks such as foreign capital inflow and the deterioration of the terms of trade. The second variant, presented in Section 3 of the paper, introduces government, savings and investment in the basic framework. The empirical implementation is based on a macroeconomic social accounting matrix (SAM) for Indonesia in 2002. Concluding remarks are made in Section 4.

\section{A Basic Model of a Small Open Economy}

In this section we consider the simplest model of a small open economy. We rely on the Salter-Swan framework, which provides a foundation for the study of the impact of macroeconomic imbalances and adjustment policies on the real sector of a small open economy. We then present an analytical expression of the model before proceeding to numerical implementation.

\footnotetext{
${ }^{4}$ Because it refers to one country with two sectors of production and three goods (Devarajan, Lewis and Robinson 1990:627).
} 


\subsection{The Salter-Swan Framework}

This single-country model (as opposed to multi-country trade model) represents a significant improvement on the standard neoclassical trade model which often leads to implausible empirical results. Such results are due to two basic assumptions. The first assumption states that all goods are tradable while the second implies perfect substitutability between foreign and domestic goods. These two assumptions imply the law of one price according to which domestic prices of tradable goods and services are determined by the world market.

Crucial within the Salter-Swan framework is the distinction between tradable and non-tradable goods and services. Non-tradable are goods and services whose prices are determined by supply and demand conditions within domestic markets. Prices for tradable goods are determined by the world market. The fact that a good is non-tradable may be due to its nature (i.e. public services or construction) or to prohibitive transport costs that keep it off the world market. Thus, some policy changes can cause some goods to switch categories.

The standard Salter-Swan model is a two-sector, general equilibrium model involving three types of goods: a non-tradable; an exportable and an importable good. The country is assumed small vis-à-vis international trade, and therefore faces a perfectly elastic excess supply from the rest of the world. In other words, it cannot affect the terms at which it is trading with the rest of the world. Exportable and importable goods can therefore be aggregated in a single class of good, tradable, using world prices as weights. The institutional framework replicates a perfectly competitive economy with three representative agents: (1) a producer who maximizes revenue subject to technical feasibility and primary factor endowment; (2) a consumer who maximizes utility subject to an overall budget constraint; and (3) the rest of the world. The equilibrium is assumed to be a full employment equilibrium. Factor and commodity prices are sufficiently flexible to maintain this status. Therefore, there is no need to explicitly model factor markets.

The standard Salter-Swan model focuses on the effects of external shocks on the real exchange rate which ultimately directs resource allocation within the economy. The 
underlying assumptions describe the best of all worlds: perfect competition at home and free trade abroad. Because the country is assumed small, all tradable goods can be aggregated into a single good. The trade balance is exogenous. Factor homogeneity combined with price flexibility ensures that all markets clear. Finally, domestic and foreign goods are perfect substitutes in consumption.

Some of the assumptions underlying the standard Salter-Swan model limit its applicability to the study of trade policy in developing countries. Disaggregating the tradable sector into exportable and importable and distinguishing these from non-tradable commodities lead to two relative prices that change independently from each other even if world prices are given. Furthermore, the real exchange rate upon which the analysis focuses is not a policy instrument directly accessible to the government. The model therefore does not include policy instruments such as taxes nor does it permit consideration of macroeconomic effects (Devarajan, Lewis and Robinson 1990: 638). The basic model could therefore be extended either by relaxing some of the assumptions deemed too restrictive or by adding actors and or markets depending on the issues at hand. For now, we focus on relaxing the assumption of perfect substitution between domestic and foreign goods as formulated in de Melo and Robinson (1989). In Section 3, we consider an additional actor (government) and a modification of spending behavior of domestic actors to allow for saving and investment.

\subsection{Analytical Expression}

Both the standard Salter-Swan model described above and the core extension under consideration are structured by the two most fundamental principles of economics: optimization and equilibrium. We thus present the structure of the model in three blocks: (1) the production possibilities that determine the optimal allocation of resources between the production of home goods and exports, (2) the consumption possibilities, and (3) equilibrium conditions. 


\section{Production Possibilities}

It is assumed that the output $\mathrm{X}_{\mathrm{s}}$, which is fixed in the short run, is either consumed locally or exported. The variables $X_{d}$ and $X_{e}$ stand respectively for the amount of output supplied to the domestic market and the amount exported. Assuming aggregate output is fixed in the short run is equivalent to assuming full employment of all primary factors of production. Thus factor markets are not modeled explicitly. The production possibility frontier is described by equation (2.1) as a constant elasticity transformation (CET) function where the elasticity is given by $\omega=\frac{1}{\phi-1}$.

$$
X_{s}=A_{x}\left[\alpha X_{e}^{\phi}+(1-\alpha) X_{d}^{\phi}\right]^{\frac{1}{\phi}}
$$

Since the producer is assumed to maximize profit subject to the above technical transformability constraint and marketing opportunities available at home and abroad, the optimal ratio of exports to domestic sales is given by the following equation ${ }^{5}$.

$$
\frac{X_{e}}{X_{d}}=\left[\left(\frac{1-\alpha}{\alpha}\right) \frac{P_{e}}{P_{d}}\right]^{\frac{1}{\phi-1}}
$$

where the domestic price of exports is defined by equation (2.3) as the exchange rate, $R$, times the world price of exports, $\pi_{\mathrm{e}}$.

$$
P_{e}=R \pi_{e}
$$

The nominal value of aggregate output is given by equation (2.4) where $\mathrm{P}_{\mathrm{x}}$ may be interpreted as a gross domestic product (GDP) deflator ${ }^{6}$.

$$
P_{x} X_{s}=\left(P_{e} X_{e}+P_{d} X_{d}\right)
$$

\footnotetext{
${ }_{6}^{5}$ For a derivation of this result see Essama-Nssah (1991a: 48).

6 The optimal value of GDP can be defined by the following envelope function: $G D P=\max \left\{P_{e} X_{e}+P_{d} X_{d}\right.$ s.t. $\left.X_{s}=A_{x}\left[\alpha X_{e}^{\phi}+(1-\alpha) X_{d}^{\phi}\right]^{\frac{1}{\phi}}\right\} \quad$ This implies the following expression for the deflator: $P_{x}=A_{x}^{-1}\left[\alpha^{-\omega} P_{e}^{(\omega+1)}+(1-\alpha)^{-\omega} P_{d}^{(\omega+1)}\right] \frac{1}{\omega+1}$.
} 


\section{Consumption Possibilities}

The analysis of the consumption possibilities is analogous to that of production possibilities. The consumer is supposed to minimize the cost of a composite consumption good which is defined as a constant elasticity of substitution (CES) aggregate of imports and domestic goods. The aggregation function is given by equation 2.5 . The elasticity of substitution is defined as: $\sigma=\frac{1}{1+\rho}$.

$$
Q_{s}=B_{q}\left[\beta Q_{m}^{-\rho}+(1-\beta) D_{x}^{-\rho}\right]^{-\frac{1}{\rho}}
$$

The optimal ratio of imports to domestic goods (in consumption) is determined by the relative price of domestic goods with respect to imports as shown in the following equation.

$$
\frac{Q_{m}}{D_{x}}=\left[\left(\frac{\beta}{1-\beta}\right) \frac{P_{d}}{P_{m}}\right]^{\frac{1}{1+\rho}}
$$

The domestic price of imports is defined in a manner analogous to the definition of the domestic price of exports (equation 2.7). It is equal to the exchange rate times the world price of imports.

$$
P_{m}=R \pi_{m}
$$

Equation 2.8 defines the nominal value of the composite consumption good.

$$
P_{q} Q_{s}=\left(P_{m} Q_{m}+P_{d} X_{d}\right)
$$

According to equation 2.9, total income of the household is equal to GDP plus the local currency equivalent of the balance of trade $\left(\mathrm{S}_{\mathrm{f}}\right)$.

$$
Y_{h}=P_{x} X_{s}+R S_{f}
$$

Assuming that the household does not save any part of its income, equation (2.10) states that household demand for the composite consumption good is equal to total household income divided by the price of the composite good ${ }^{7}$.

\footnotetext{
${ }^{7}$ In a manner analogous to the case of the GDP deflator, it can be shown that this consumer price index can be written as (Essama-Nssah 1991a:51): $P_{q}=B_{q}^{-1}\left[\beta^{\sigma} P_{m}^{(1-\sigma)}+(1-\beta)^{\sigma} P_{d}^{(1-\sigma)}\right]^{\frac{1}{1-\sigma}}$.
} 


$$
Q_{d}=\frac{Y_{h}}{P_{q}}
$$

\section{Equilibrium}

There are three equilibrium conditions that must hold in addition to the fact that the household budget constraint is satisfied as implied by equation (2.10). These conditions are stated in equations (2.11)-(2.13): The supply of home good is equal to its demand, similarly for the composite consumption good. Foreign saving is equal to the world market value of imports minus that of exports.

$$
X_{d}=D_{x}
$$

$$
Q_{s}=Q_{d}
$$

$$
\pi_{m} Q_{m}-\pi_{e} X_{e}=S_{f}
$$

\subsection{Numerical Implementation}

\section{Data Framework and Closure}

Numerical implementation entails fitting the above described analytical structure to a data set representing the state of the economy for the period under consideration. Usually, it is believed that the data set represents base year equilibrium. The resulting empirical model may then be used to conduct counterfactual simulations in order to examine the likely change in equilibrium values of endogenous variables induced by changes in some exogenous variables. One may also conduct sensitivity analysis to study the implications of changing the values of some structural parameters underlying the base line results.

The necessary data for an empirical economy-wide model must be organized in a frame that reflects the circular flow of economic activity for the chosen year. The social accounting matrix (SAM) offers such a framework. It provides an analytically integrated data set which reflects various aspects of the economy such as production, consumption, trade, accumulation and income distribution. A SAM is a square matrix, the dimension of which is determined by the institutional setting underlying the economy under consideration. Each account is represented by a combination of one row and one column 
with the same label. Each entry represents a payment to a row-account by a columnaccount. Thus, all receipts into an account are read along the corresponding row while payments by the same account are recorded in the corresponding column. In accordance to the principles of double-entry bookkeeping, the whole construct is subject to a consistency restriction which make the column sums equal to the corresponding row sums. This restriction also means that the SAM obeys Walras' Law in the sense that, for a n-dimensional matrix, if the (n-1) accounts balance, so must the last one. Table 2.1 shows the structure of the SAM underlying the core model.

Table 2.1. Structure of the SAM Underlying the Core Model

\begin{tabular}{|l|c|c|c|c|c|}
\hline Activity & Commodity & Household & Rest of World & Total \\
\hline Commodity & & Domestic Sales & & Exports & Total Sales \\
\hline Household & $\begin{array}{c}\text { Payments to } \\
\text { Factors of } \\
\text { Production }\end{array}$ & & $\begin{array}{c}\text { Household } \\
\text { Consumption }\end{array}$ & & $\begin{array}{c}\text { Total } \\
\text { Absorption }\end{array}$ \\
\hline Rest of World & & Imports & & Trade & $\begin{array}{c}\text { Total } \\
\text { Household } \\
\text { Income }\end{array}$ \\
& Total Factor & $\begin{array}{c}\text { Total Supply of } \\
\text { Consumption } \\
\text { Total }\end{array}$ & $\begin{array}{c}\text { Total } \\
\text { Household } \\
\text { Expenditure }\end{array}$ & $\begin{array}{c}\text { Expenditure by } \\
\text { Rest of World }\end{array}$ & $\begin{array}{c}\text { Total Earnings } \\
\text { of Rest of the } \\
\text { World }\end{array}$ \\
& & Goods & & & \\
\hline
\end{tabular}

Given the base year values, the first step in numerical implementation entails model validation whereby structural parameters are suitably chosen such that the base run replicates base year values of endogenous variables as closely as possible (given base year values of exogenous variables). As stated earlier, it is desirable that such a solution be unique, which generally requires that the number of independent equations be equal to the number of endogenous variables. EViews syntax enforces this idea by requiring $a$ 
one-to-one mapping between equations and endogenous variables ${ }^{8}$. Such a map is a function of model closure, which in turn depends on assumptions made about the functioning of the economy.

Table 2.2. Baseline Data

\begin{tabular}{|l|c|c|c|c|c|}
\hline & Activity & Commodity & Household & Rest of World & Total \\
\hline Activity & & 75 & & 25 & 100 \\
\hline Commodity & & & 100 & & 100 \\
\hline Household & 100 & & & 0 & 100 \\
\hline Rest of World & & 25 & & & 25 \\
\hline Total & 100 & 100 & 100 & 25 & \\
\hline
\end{tabular}

Data Source: de Melo and Robinson (1989: 59)

The following assumptions will help determine some exogenous variables. The small country assumption implies that both the world price of exports $\left(\pi_{\mathrm{e}}\right)$ and imports $\left(\pi_{\mathrm{m}}\right)$ are exogenous. If we choose the aggregate consumption good as numéraire, then its price $\left(\mathrm{P}_{\mathrm{q}}\right)$ can be set exogenously equal to unity. Full employment of primary factors of production means that real output is fixed. Therefore $\mathrm{X}_{\mathrm{s}}$ is taken to be exogenous. Furthermore, we assume that nominal exchange rate adjusts to bring the trade account into balance. This assumption makes the balance of trade $\left(\mathrm{S}_{\mathrm{f}}\right)$ an exogenous variable. Box 2.1 shows the core model in EViews. The model consists of 10 equations and 10 endogenous variables. The two equilibrium conditions 2.11 and 2.12 are handled implicitly by letting a single variable stand for both supply and demand. Finally, it can be shown that the three equilibrium conditions are not linearly independent by Walras' Law. Therefore any one of those can be left out of the system of equation describing the model.

We now present the entire program designed to set up the model, produce the baseline solution and simulate structural adjustment to external shocks, namely an increase in foreign transfers and a deterioration in the terms of trade. The data base is presented in Table 2.2. The program includes four basic components. The first sets up

\footnotetext{
${ }^{8} \mathrm{~A}$ model is termed square when the number of endogenous variables is equal to the number of independent equations.
} 
the social accounting matrix. The second specifies the CGE model. The third component initializes the variables and calibrates the model under five different cases depending on the assumed values of the transformation and substitution elasticities. The final component produces the base solution and performs the desired simulations.

\section{Box 2.1 The Core Model in EViews}

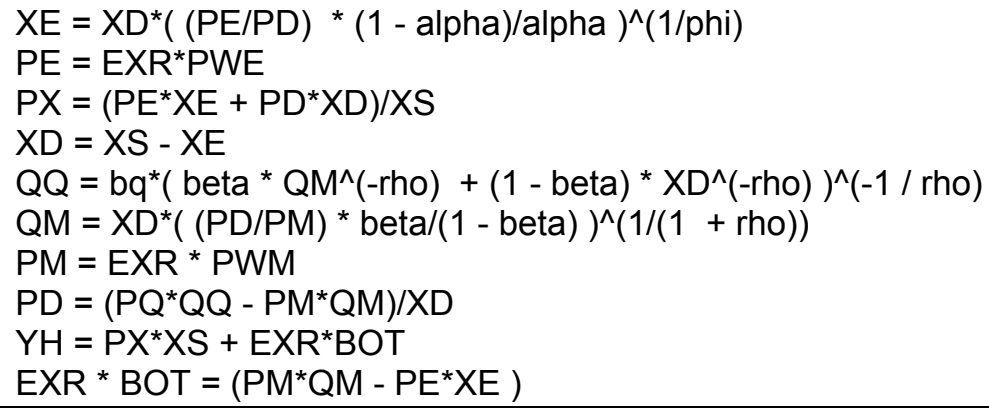

To begin with, we use the following command to create a workfile called DMR89. The option U for "undated" is selected since we are not dealing with time series. The range of the workfile is set to 5 because we will solve and simulate the model under five different values of the key elasticities.

\section{WORKFILE DMR89 U 5}

\section{Baseline Data Processing}

In setting up the SAM, we rely on the syntax governing the matrix object in EViews. Since there are four accounts in the SAM we create a $5 \times 5$ matrix where the fifth element stands for the total. The following labels are used: (1) ACT Activity; (2). COM Commodity; (3). HHD Household; (4). ROW World; (5). TOT Total. The following two commands declare the matrix and the associated column vectors:

MATRIX (5,5) MSAM

FOR \%AC ACT COM HHD ROW TOT NEXT VECTOR(5) V\{\%AC $\}$

The following 9 commands fill in the column vectors with relevant base year data. The total of each column is computed as the sum of the previous entries in the account. 
$\operatorname{VACT}(3)=100$

$\operatorname{VACT}(5)=@ S U M(V A C T)$

$\operatorname{VCOM}(1)=75$

$\operatorname{VCOM}(4)=25$

$\operatorname{VCOM}(5)=@ S U M(V C O M)$

$\operatorname{VHHD}(2)=100$

VHHD(5)=@SUM(VHHD)

$\operatorname{VROW}(1)=25$

VROW(5)=@SUM $($ VROW $)$

The following loop loads the vectors in the SAM. To avoid cluttering the workfile, each vector is deleted after its placement in the SAM.

$! \mathrm{COL}=1$

FOR \%AC ACT COM HHD ROW

COLPLACE(MSAM, $\backslash\{\% A C\}, ! C O L)$

DELETE $\vee\{\% A C\}$

NEXT

$! \mathrm{COL}=! \mathrm{COL}+1$

The following loop computes the row total separately and places the results in a column vector VTOT. The vector is also deleted once it has been placed in the SAM.

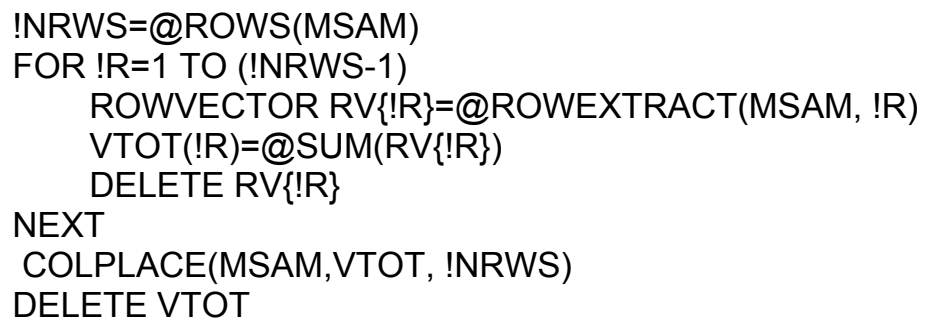

One has the option of turning the matrix into a table using the FREEZE command and labeling both rows and columns within a single loop. This is done by the next chunk of program.

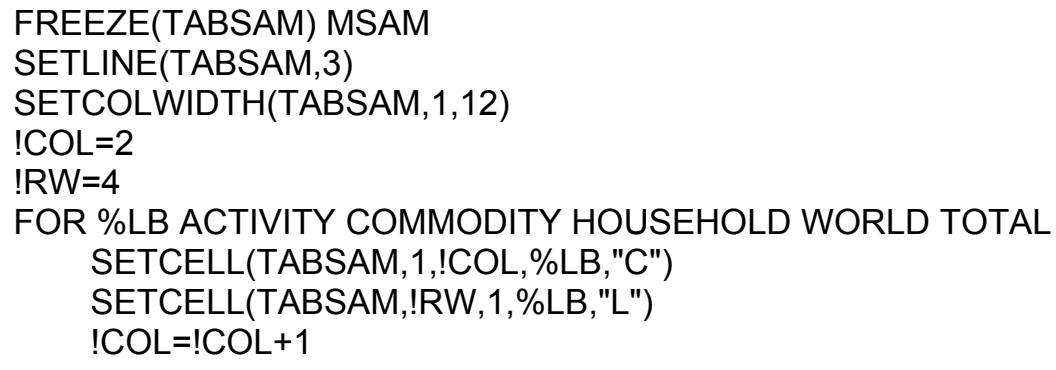




\section{NEXT}

$! R W=! R W+1$

\section{Model Specification}

The first step in model specification is to declare the model object by letting the model name follow the keyword "MODEL" as in the following statement: MODEL DMR. Once the model has been declared, the APPEND command is used to enter the relevant equations based on the selected closure. We organize the model specification in three blocks: (1) production possibilities; (2) consumption possibilities; and (3) system constraints. The three blocks are presented in Box 2.2 below.

\section{Box 2.2. Model Specification in EViews}

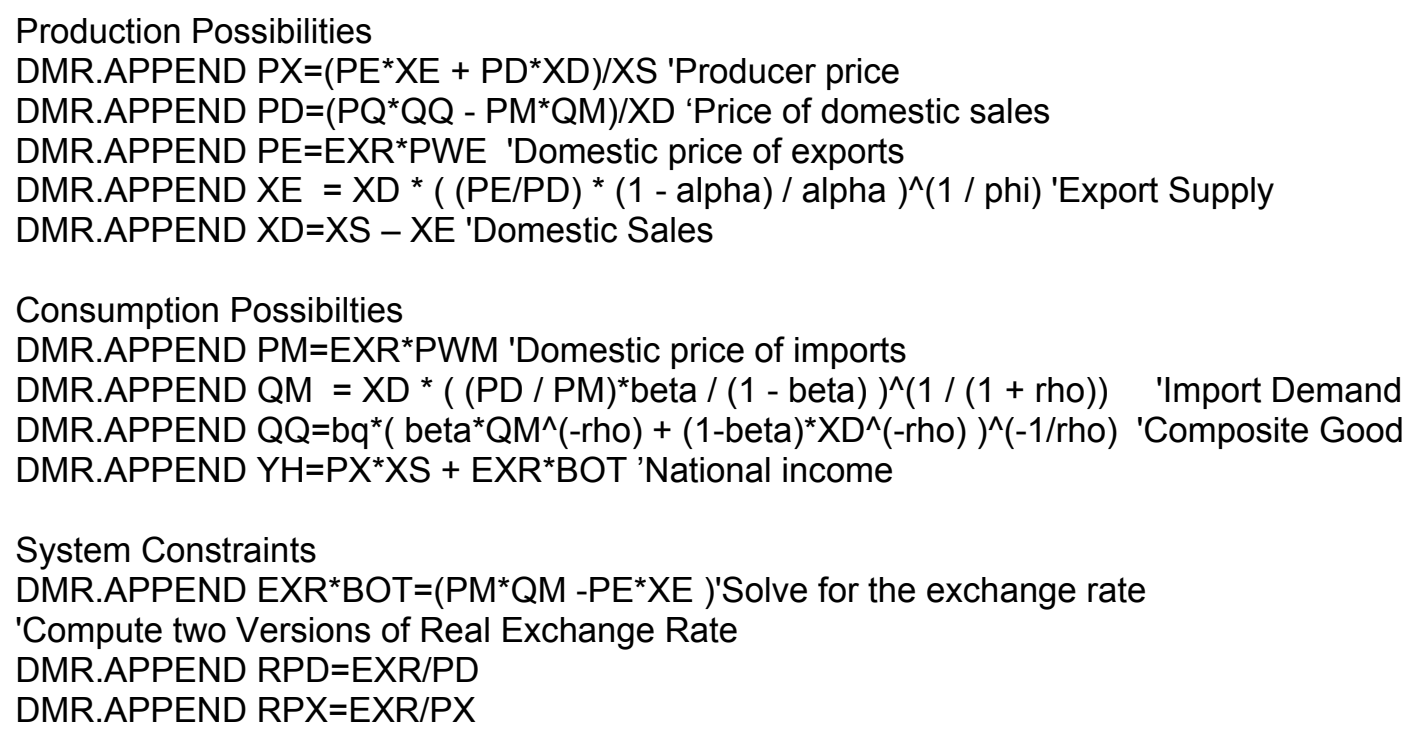

We have appended to the model two more equations which do not appear in Box 2.1. The two equations allow us to consider two versions of the real exchange rate defined as the nominal exchange rate deflated by a domestic price index. We consider two indices, the price of domestic sales and the GDP deflator.

The treatment of system constraints deserves further explanation. In general this is where one specifies market equilibrium and other conditions governing macroeconomic balance. As explained earlier, factor market equilibrium is handled 
implicitly by making the output variable (XS) exogenous. Domestic market equilibrium is also treated implicitly by letting the variable XD stand for both supply and demand. A similar treatment is reserved to the material balance for the composite consumption good. Here the variable QQ stand for both supply and demand. The only condition we state explicitly relates to the balance of trade. As written, it implies that the nominal exchange rate is an endogenous variable. This is due the syntactical rule according to which the variable appearing first in the specification of an equation is considered by EViews as the endogenous variable defined by the given equation.

\section{Calibration, Initialization and Baseline Solution}

The mathematical structure presented above hinges on a few parameters (shift, share and elasticity) that must be specified in order to make the model numerically compatible with the base year observations contained in the SAM. This entails a process known as calibration whereby the values of the structural parameters are expressed as functions of the relevant model variables. When base year values of variable are used in these expressions and the model is solved using the resulting parameter values, we obtain the baseline solution.

The following block of statements does two things. It declares all variables using a loop controlled by a string variable the values of which correspond to the names of the variables. The remaining statements assign initial values to the declared variables.

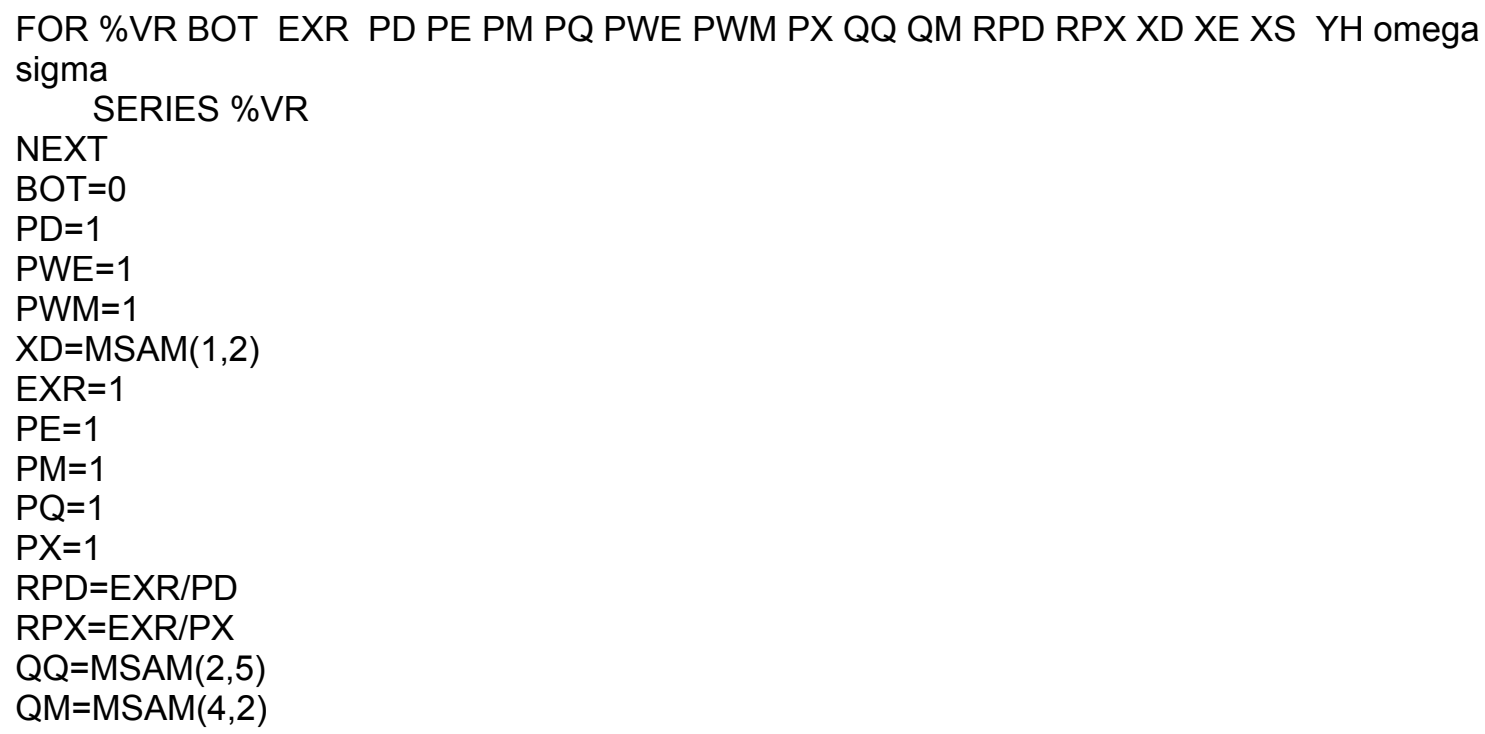


$X D=M S A M(1,2)$

$X E=M S A M(1,4)$

$X S=M S A M(1,5)$

$\mathrm{YH}=\mathrm{MSAM}(3,5)$

For the purpose of calibration, it seems convenient to create a satellite model to do the job. We call this model CALIBER. Since we would like to calibrate the model for five different sets of values for the transformation elasticity (omega) and the elasticity of substitution (sigma) we use the FILL command to create the two series. We will see that these parameters are key determinants of the way the economy responds to shocks and policies. The first command in the next block declares the calibration model. The next two create 5 different structural cases. The APPEND statements specify the calibration model. Finally, setting the scenario to ACTUALS and invoking the SOLVE statement assigns solution values to the parameters.

\section{MODEL CALIBER}

omega.fill $0.2,0.5,2,5,5000000^{\prime}$

sigma.fill $0.2,0.5,2,5,5$

CALIBER.APPEND rho $=(1 /$ sigma $)-1$

CALIBER.APPEND phi $=(1 /$ omega $)+1$

CALIBER.APPEND alpha $=1 /\left(1+(\mathrm{PD} / \mathrm{PE})^{*}(\mathrm{XE} / \mathrm{XD})^{\wedge}(\mathrm{phi})\right)^{\prime}$ Share for the CET function

CALIBER.APPEND ax $=X S /\left(\text { alpha* } X E^{\wedge} \text { phi }+(1 \text {-alpha })^{\star} X D^{\wedge} \text { phi }\right)^{\wedge}(1 / p h i)$ 'Scale factor for the CET function

CALIBER.APPEND beta $=\left((\mathrm{PM} / \mathrm{PD})^{\star}(\mathrm{QM} / \mathrm{XD})^{\wedge}(1+\mathrm{rho})\right) /\left(1+(\mathrm{PM} / \mathrm{PD})^{\star}(\mathrm{QM} / \mathrm{XD})^{\wedge}(\right.$ rho +1$\left.)\right)$ 'Share for the CES function

CALIBER.APPEND bq $=\mathrm{QQ} /\left(\text { beta }^{*} \mathrm{QM}^{\wedge}(- \text { rho })+(1-\text { beta })^{\star} X D^{\wedge}(- \text {-rho })\right)^{\wedge}(-1 /$ rho $)$ 'Scale factor for the CES function

CALIBER.SCENARIO ACTUALS

CALIBER.SOLVE $(\mathrm{s}=\mathrm{d}, \mathrm{d}=\mathrm{s}, \mathrm{o}=\mathrm{n})$

The baseline solution of the model DMR is obtained from the first three statements in the next block of commands. The very first command set the solution options as follows: (1) $\mathrm{s}=\mathrm{d}$ (deterministic solution); (2) $\mathrm{d}=\mathrm{s}$ (static solution); (3) $\mathrm{c}=1 \mathrm{e}-15$ (convergence criterion); and (4) $\mathrm{o}=\mathrm{n}$ (Newton solution algorithm). The last two statements in that same block create a table, called BASELINE, which contains both actual and baseline solution values of all the endogenous variables.

DMR.SOLVEOPT $(s=d, d=s, c=1 e-15, o=n)$

DMR.SCENARIO(c) BASELINE 'Option "c" makes the baseline scenario the comparison scenario SOLVE DMR

DMR.MAKEGROUP(a) BASEGRP @ENDOG

FREEZE(BASELINE) BASEGRP 
Table 2.3. Baseline Solution

\begin{tabular}{ccccccccccc}
\hline Omega & Sigma & EXR & PD & PX & RPD & RPX & XD & XE & QM & QQ \\
\hline 0.2 & 0.2 & 1.00 & 1.00 & 1.00 & 1.00 & 1.00 & 75.00 & 25.00 & 25.00 & 100.00 \\
0.5 & 0.5 & 1.00 & 1.00 & 1.00 & 1.00 & 1.00 & 75.00 & 25.00 & 25.00 & 100.00 \\
2 & 2 & 1.00 & 1.00 & 1.00 & 1.00 & 1.00 & 75.00 & 25.00 & 25.00 & 100.00 \\
5 & 5 & 1.00 & 1.00 & 1.00 & 1.00 & 1.00 & 75.00 & 25.00 & 25.00 & 100.00 \\
5000000 & 5 & 1.00 & 1.00 & 1.00 & 1.00 & 1.00 & 75.00 & 25.00 & 25.00 & 100.00 \\
\hline
\end{tabular}

Source : Computed (Variable definition: Exchange rate, EXR; Price of Domestic sales, PD; GDP deflator, PX; Real exchange rate based on price of domestic sales, RPD; Real Exchange Rate based on GDP deflator; Domestic sales, XD; Exports, XE; Imports, QM; Absorption, QQ).

Table 2.3 above confirms that model calibration was successful since the baseline solution reproduces the values observed in the SAM.

\section{Structural Adjustment to External Shocks}

When an economy undergoes a shock (be it an exogenous or a policy shock), its structure may change significantly and such a change is likely to have significant welfare implications. We consider first the implications of an increase in foreign transfers as represented by an increase in the exogenous variable BOT from 0 to 10 . The implementation of this situation in EViews is handled by the following six lines of code.

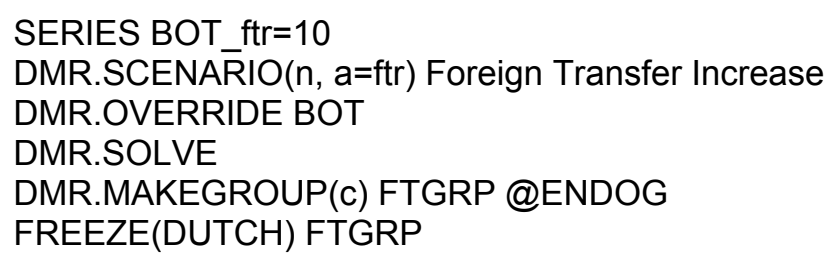

The impact of an increase in foreign transfer is assessed by comparing the baseline solution (with BOT=0) and the solution when BOT=10. The model scenario 9

\footnotetext{
${ }^{9}$ The distinction between data associated with different scenarios is based on the aliasing rule. This rule entails a modification of the names of model variables by adding an underline followed by an alphanumeric suffix. This rule is specified by the "a" option in the scenario statement. In our case the option is stated as $\mathrm{a}=\mathrm{ftr}$ (for foreign transfers). This suffix is used by EViews to modify the name of endogenous variables under this scenario. It is important to note that overridden exogenous variables must be created with the proper suffix prior to invoking the override command. Otherwise, EViews issues an error message. There
} 
allows us to do this without overwriting previous data. Essentially, what the above code does is to: (1) specify a scenario called "Foreign Transfer Increase"; (2) create an override variable BOT_ftr to hold the new values of the exogenous variable; (3) specify BOT as an override series for the scenario; (4) solve the model again; (5) store the results in a group called FTGRP (option "c" causes EViews to include values from the comparison scenario); and (6) turn the group into a table called DUTCH ${ }^{10}$.

Table 2.4. Welfare and Structural Implications of an Increase in Foreign Transfers

\begin{tabular}{ccccccccccc}
\hline Omega & Sigma & EXR & PD & PX & RPD & RPX & XD & XE & QM & QQ \\
\hline 0.2 & 0.2 & 0.43 & 1.21 & 1.04 & 0.36 & 0.42 & 78.06 & 21.94 & 31.94 & 108.08 \\
0.5 & 0.5 & 0.71 & 1.11 & 1.02 & 0.64 & 0.70 & 77.67 & 22.33 & 32.33 & 108.99 \\
2 & 2 & 0.91 & 1.04 & 1.01 & 0.87 & 0.90 & 76.63 & 23.37 & 33.37 & 109.61 \\
5 & 5 & 0.96 & 1.02 & 1.00 & 0.94 & 0.96 & 75.92 & 24.08 & 34.08 & 109.80 \\
5000000 & 5 & 0.96 & 1.02 & 1.00 & 0.94 & 0.96 & 76.08 & 23.92 & 33.92 & 109.81 \\
\hline
\end{tabular}

Source : Computed

Table 2.4 contains the welfare and structural implications of an increase in foreign transfer equivalent to 10 percent of base year GDP under five different structures of the economy depending on the assumed values of the elasticities of the export transformation (omega) and import substitution (sigma). Based on the chosen indicator QQ, it is clear that welfare is uniformly higher in this case than in the baseline scenario. Also, the higher the elasticities of transformation and substitution, the higher the increase in welfare ${ }^{11}$.

are two special scenarios known as actuals and baseline. These scenarios cannot contain overrides or excluded variables. The actuals scenario writes the solution for the endogenous variables back into series with the same names as model variables. This creates a risk of losing original (or historical data). The baseline scenario modifies names according to the prevailing aliasing rule. By default, the baseline scenario adds an underline and a zero to the names of the endogenous variables.

${ }^{10}$ In reference to the "Dutch disease" phenomenon representing the deterioration of the Netherlands' export competitiveness associated with the exploitation of natural gas fields in the 1970s (Benjamin and Devarajan 1985).

${ }^{11}$ De Melo and Robinson (1989:59) present similar results based on a solution obtained with GAMS (General Algebraic Modeling System). They note that, in the limit, when the elasticity of export transformation is infinite, the increase in welfare is equal to the transfer itself. 
The structural adjustment of the economy to this shock hinges crucially on the size of the elasticity of import substitution. Devarajan and Lewis (1990: 633-638) present a qualitative analysis which clarifies the role of the elasticity of import substitution in this adjustment process. Given that the foreign transfer goes entirely to the consumer, there will be an increase in total consumption (and hence welfare) as noted above. The structure of the new equilibrium in terms of the combination of domestic goods and imports depends on the aggregation function defining the composite consumption good. When the elasticity of import substitution is close to infinity the domestic good and imports are almost perfect substitutes. Thus all extra foreign exchange will finance imports and there will be no change in the amount of domestic good consumed. If the elasticity of substitution were zero, the domestic good and imports would be perfect complements and more of both would be consumed in the new equilibrium. The increase in the demand for the domestic good requires an increase in its price (relative to that of exports). This leads to real appreciation of the exchange rate. On the production side, resources will shift out of the export sector to meet the increase in the demand for the domestic good. This adjustment is known as the Dutch disease. It is clear that the results presented in Table 2.4 fall within the two limits described here. Real appreciation is more significant for lower values of the elasticity of substitution. In short, an increase in foreign transfers will cause real appreciation or not depending on the value of the elasticity of substitution (sigma). In the case of real appreciation, both the production and consumption of the domestic good increase along with imports while the supply of exports declines. If there is no appreciation the entire shock is absorbed by an increase in imports.

The analysis of a deterioration of the terms of trade is entirely analogous to that of an inflow of foreign exchange. The next chunk of code implements a 10 percent increase in the world price of imports. The corresponding simulation results are presented in Table 2.5 below.

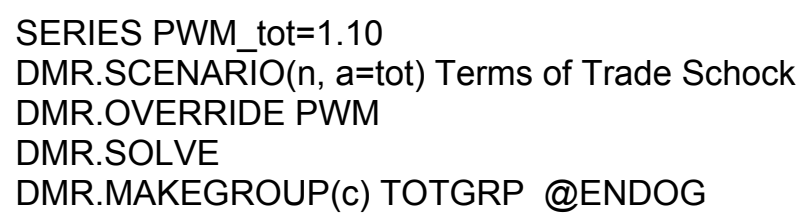


FREEZE(DETOT) TOTGRP

Table 2.5. Welfare and Structural Implications of a Deterioration of the Terms of Trade

\begin{tabular}{ccccccccccc}
\hline Omega & Sigma & EXR & PD & PX & RPD & RPX & XD & XE & QM & QQ \\
\hline 0.2 & 0.2 & 1.13 & .92 & .97 & 1.23 & 1.16 & 74.34 & 25.66 & 23.32 & 97.49 \\
0.5 & 0.5 & 1.02 & .96 & .98 & 1.06 & 1.04 & 74.64 & 25.36 & 23.05 & 97.59 \\
2 & 2 & 0.95 & .99 & .98 & .96 & .97 & 75.44 & 24.56 & 22.32 & 97.70 \\
5 & 5 & 0.93 & .99 & .98 & .94 & .95 & 76.01 & 23.99 & 21.81 & 97.78 \\
5000000 & 5 & 0.93 & .99 & 98 & .94 & .95 & 76.17 & 23.83 & 21.66 & 97.79 \\
\hline
\end{tabular}

Source : Computed

As a result of this adverse terms of trade shock, the same amount of exports would now buy fewer imports. In order to increase exports to pay for more expensive imports there has to be real depreciation of the exchange rate (a decrease in the price of the domestic good relative to the price of the export good). This will induce a resource movement away from the domestic to the export sector. Whether or not there is real depreciation depends on the relative importance of the income and substitution effects associated with the terms of trade shock. Devarajan, Lewis and Robinson (1990:636) explain that the income effect would dominate the substitution effect when the elasticity of import substitution is less than one. As shown in table 2.5, the domestic sector would contract while the export sector would expand. There would be no structural change in the economy when the elasticity of substitution is equal to one. When this elasticity is greater than one, the substitution effect dominates the income effect and the export sector contracts while the domestic sector expands. These results are also confirmed by table 2.5 .

The above discussion reveals that the relevance of the policy response to external shocks depends on the structure of the economy. When the elasticity of import substitution is less than one, the policy advice is to depreciate the real exchange rate to mitigate the effects of an adverse terms of trade shock. Otherwise, real exchange appreciation is advocated for the substitution of domestic goods for more expensive 
imports. This would lead to a contraction of the aggregate volume of trade (Devarajan, Lewis and Robinson 1990: 637).

\section{Including Government, Savings and Investment}

As stated earlier, the simple model described above can be further extended in several dimensions. One may add new economic agents, modify the institutional framework or the behavior of previously included agents depending on the issue at hand. We now consider adding a government and modifying the behavior of three agents (the consumer, the government and the rest of the world) by assuming that they save part of their income. The institutional framework now includes a reduced-form capital market that transforms savings into investment. The inclusion of the government allows the consideration of fiscal issues linked to available tax instruments, and to government expenditure. All these extensions necessarily entail a modification of the model structure. These modifications are translated through new SAM accounts, and new equations (Table 3.1 and Box 3.1).

\subsection{Structure}

Table 3.1. Structure of the SAM Underlying the Extended Model

\begin{tabular}{|c|c|c|c|c|c|c|c|}
\hline & Activity & Commodity & Household & Government & Investment & World & Total \\
\hline Activity & & $\begin{array}{l}\text { Domestic } \\
\text { Sales }\end{array}$ & & $\begin{array}{l}\text { Export } \\
\text { Subsidies }\end{array}$ & & Exports & Total Sales \\
\hline Commodity & & & $\begin{array}{l}\text { Household } \\
\text { Consumption }\end{array}$ & $\begin{array}{l}\text { Government } \\
\text { Consumption }\end{array}$ & Investment & & $\begin{array}{l}\text { Total } \\
\text { Absorption }\end{array}$ \\
\hline Household & $\begin{array}{l}\text { GDP at } \\
\text { Factor } \\
\text { Cost }\end{array}$ & & & Transfers & & $\begin{array}{l}\text { Foreign } \\
\text { Remittances }\end{array}$ & $\begin{array}{l}\text { Household } \\
\text { Income }\end{array}$ \\
\hline Government & $\begin{array}{l}\text { Indirect } \\
\text { Taxes }\end{array}$ & Tariffs & Income Tax & & & & $\begin{array}{l}\text { Government } \\
\text { Revenue }\end{array}$ \\
\hline Savings & & & $\begin{array}{l}\text { Household } \\
\text { Savings }\end{array}$ & $\begin{array}{l}\text { Government } \\
\text { Savings }\end{array}$ & & $\begin{array}{l}\text { Foreign } \\
\text { Savings }\end{array}$ & $\begin{array}{l}\text { Total } \\
\text { Savings }\end{array}$ \\
\hline World & & Imports & & & & & $\begin{array}{l}\text { Total } \\
\text { Imports }\end{array}$ \\
\hline Total & $\begin{array}{l}\text { GDP } \\
\text { Market } \\
\text { Prices }\end{array}$ & $\begin{array}{l}\text { Total } \\
\text { Supply }\end{array}$ & $\begin{array}{l}\text { Total } \\
\text { Household } \\
\text { Expenditure }\end{array}$ & $\begin{array}{l}\text { Government } \\
\text { Expenditure }\end{array}$ & $\begin{array}{l}\text { Total } \\
\text { Investment }\end{array}$ & $\begin{array}{l}\text { Total } \\
\text { Foreign } \\
\text { Exchange }\end{array}$ & \\
\hline
\end{tabular}


Box 3.1. A Static Model with Government, Savings and Investment

$$
\begin{array}{|ll}
\hline \text { Production Possibilities } \\
\text { (1) } & X_{s}=A_{x}\left[\alpha X_{e}^{\phi}+(1-\alpha) X_{d}^{\phi}\right]^{\frac{1}{\phi}} \\
(2) & \frac{X_{e}}{X_{d}}=\left[\left(\frac{1-\alpha}{\alpha}\right) \frac{P_{e}}{P_{t}}\right]^{\frac{1}{\phi-1}} \\
(3) & P_{e}=R\left(1+t_{e}\right) \pi_{e} \\
(4) & P_{x} X_{s}=\left(P_{e} X_{e}+P_{t} X_{d}\right)
\end{array}
$$

Consumption Possibilities

$$
\begin{aligned}
& Q_{s}=B_{q}\left[\beta Q_{m}^{-\rho}+(1-\beta) D_{x}^{-\rho}\right]^{-\frac{1}{\rho}} \\
& \frac{Q_{m}}{D_{x}}=\left[\left(\frac{\beta}{1-\beta}\right) \frac{P_{t}}{P_{m}}\right]^{\frac{1}{1+\rho}} \\
& P_{m}=R\left(1+t_{m}\right) \pi_{m} \\
& P_{q} Q_{s}=\left(P_{m} Q_{m}+P_{t} D_{x}\right) \\
& Y_{h}=\left(P_{x} X_{s}-\frac{t_{d}}{1+t_{d}} P_{t} X_{d}\right)+P_{q} T_{h g}+R T_{h f} \\
& Q_{h}=\frac{\left(1-s_{h}\right)\left(1-t_{h}\right) Y_{h}}{P_{q}} \\
& Q_{d}=Q_{h}+Q_{g}+Q_{i}
\end{aligned}
$$

Government Revenue

$$
Y_{g}=t_{m} R \pi_{m} Q_{m}+\frac{t_{d}}{1+t_{d}} P_{t} X_{d}+t_{h} Y_{h}
$$

Aggregate Saving

(13)

$$
S=S_{h} Y_{h}+S_{g}+R S_{f}
$$

\section{Equilibrium Conditions}

$$
\begin{aligned}
& X_{d}=D_{x} \\
& Q_{s}=Q_{d} \\
& \pi_{m} Q_{m}-\pi_{e} X_{e}-T_{h f}=S_{f} \\
& S_{g}=Y_{g}-P_{q} Q_{g}-P_{q} T_{h g}-t_{e} R \pi_{e} X_{e} \\
& P_{q} Q_{i}=S
\end{aligned}
$$

Compared to the SAM underlying the basic model the extended SAM includes two new accounts. The government account collects indirect production taxes from the activity account, tariffs from the commodity account and income tax from the household 
account. Total government revenue is spent on export subsidies, government consumption of goods and services, and on transfers to the household. The residual represents government savings which go into the savings account. This account also collects savings from the household and the rest of the world. As noted earlier, total savings are spent on investment.

The inclusion of savings and investment introduces an inter-temporal dimension to resource allocation which is revealed by the distinction between current and capital account. The savings-investment account is the only capital account while the rest of the accounts are current accounts. Furthermore, the intersection of the capital account and the current account reveals the dual nature of the items included in the capital account. Thus, savings represent both a current use of resources and a source of funds in the corresponding capital account. Similarly, investment in physical assets bought from the capital goods market during the current period is a source of current revenue for the commodity account and a capital expenditure for the agent who invests ${ }^{12}$.

The analytical expression of the model is presented in Box 3.1. Given the analogy between the extended and the basic model, we highlight only the new features. The introduction of various taxes changes the incentive system. All prices now include applicable taxes. The price of domestic sales $\mathrm{P}_{\mathrm{t}}$ includes indirect taxes. The domestic price of exports (equation 3 ) includes subsidies at a rate $t_{e}$, while the domestic price of imports (equation 7) includes tariffs, $t_{\mathrm{m}}$. Income tax is paid by the consumer at a rate $t_{\mathrm{h}}$. Part of disposable income is saved at a rate of $s_{h}$. This leads to the specification of the consumption function presented in equation 10 .

The variable $\mathrm{X}_{\mathrm{s}}$ is now interpreted as GDP at market prices. Since indirect taxes are paid to the government, they must be subtracted from total GDP to get GDP at factor cost which is given to the consumer (assumed owner of the factors of production). In

\footnotetext{
${ }^{12}$ In reality, the six accounts in the SAM framework presented here may be viewed as representative accounts in the sense that all can be disaggregated in accordance with the available information and the issues to be analyzed. The intersection of the saving row with the investment column represents pure capital transactions. This block is left empty here because we are not dealing with the functioning of the financial market. In principle, the block shows financing flows for each agent. Equality between a row total and the corresponding column total means that total financing from all sources (savings and borrowing) must equal total use of funds (i.e. investment in both physical and financial assets). For each agent therefore, the excess of investment over saving is accounted for by net borrowing from all sources (domestic and foreign).
} 
addition, the household may receive transfer payments from the government $\left(T_{h g}\right.$ in real terms) and from the rest of the world ( $\mathrm{T}_{\mathrm{hf}}$ in foreign currency). Total income of the household is defined in equation 9. According to equation 11, total absorption now has three components: private consumption $\left(\mathrm{Q}_{\mathrm{h}}\right)$, government consumption $\left(\mathrm{Q}_{\mathrm{g}}\right)$ and investment $\left(\mathrm{Q}_{\mathrm{i}}\right)$.

Aggregate saving is defined by equation 13 as the sum of three components: household savings, government savings and foreign savings. There are now two additional system constraints or equilibrium conditions that must be satisfied. Government saving is the difference between government revenue and government expenditures inclusive of transfers and subsidies (equation 17). The value of total investment equals total available savings (equation 18).

\subsection{Numerical Implementation ${ }^{13}$}

To illustrate the implementation of the extended model, we fit the above analytical structure to a macroeconomic SAM for Indonesia (Table 3.2). In order to close the model we keep the marginal propensity to save and all tax instruments exogenous. Transfers from the rest of the world to the household are also exogenous. In general, the macroeconomic properties of a model such as this one depend on the macro closure rule chosen. Such a rule refers to the equilibrating mechanisms governing product and factor markets as well as the following three basic macro balances: balance of trade, government budget balance and savings investment balance ${ }^{14}$.

\footnotetext{
${ }^{13}$ The full computer program is presented in the annex.

${ }^{14}$ Robinson (2003) discusses four possible macro closures for this class of models, two of which assume full employment of factors of production while the other two do not. Assuming that output is a function of two factors of production capital and labor, there are 10 potential macro closure variables: the GDP deflator, the age rate, the exchange rate, investment demand, the trade balance, labor supply, government consumption of goods and services, capital, the saving rate and the income tax rate. Macro closure rules differ on the basis of which three (the number of macro balances in the model) of these 10 variables are made endogenous, while all the rest are exogenous. The first full employment closure, also known as neoclassical considers the wage rate, the exchange rate and investment demand as endogenous variables. In the second full employment closure, the wage rate, the exchange rate and the balance of trade are endogenous. Closure rules that assume unemployment are known as Keynesian. The first rule makes the GDP deflator, the exchange rate and labor supply endogenous. For the second rule, the endogenous variables are: the GDP deflator, the trade balance and labor supply. It is worth noting that the GDP deflator is a numéraire price in the full employment case while the wage rate plays that role in the Keynesian case.
} 
Our simulations are based on the following equilibrating mechanisms: (1) The aggregate consumer good is the numéraire (thus the consumer price index is exogenously fixed to unity); (2) the domestic good market is brought to equilibrium through adjustment in the price of domestic sales; (3) factor markets are assumed to clear in the background through factor price adjustment, hence $X_{s}$ is fixed exogenously; (4) the balance of trade is exogenous so that the market for foreign exchange is brought to equilibrium by adjustment in the exchange rate; (5) for the government account, revenues are determined by the tax system, spending is exogenous while savings are determined residually (they are the equilibrating variable); (6) investment is savings-driven.

\section{Base Data}

Table 3.2. A Macroeconomic SAM for Indonesia (in 2002 Billion Rupiahs)

\begin{tabular}{|l|l|l|l|l|l|l|l|}
\hline & Activity & Commodity & Household & Government & Investment & World & Total \\
\hline Activity & & 1040070 & & & & 569942 & 1610012 \\
\hline Commodity & & & 1042148 & 132219 & 325334 & & 1499701 \\
\hline Household & 1538826 & & & & & 19246 & 1558072 \\
\hline Government & 71186 & 12005 & 110845 & & & & 194036 \\
\hline Savings & & & 405079 & 61817 & & -141562 & 325334 \\
\hline World & & 447626 & & & & & 447626 \\
\hline Total & 1610012 & 1499701 & 1558072 & 194036 & 325334 & 447626 & \\
\hline
\end{tabular}

Data Source: LDB on Line (World Bank)

\section{Implications of an Export Boom}

What might happen if the world price of exports increased by, say, 20 percent? Ceteris paribus, this would correspond to an improvement in the terms of trade. There is an income and a substitution effect associated with this change and the final outcome depends on the dominant effect. As discussed above in the case of an increase in the world price of imports, the outcome hinges on the value of the elasticity of substitution between imports and domestic goods. The increase in income induced by the 
improvement of the terms of trade would lead to an increased demand for both the home good and imports. The income effect dominates the substitution effect when the elasticity of substitution is less than one. Thus the economy would settle at a new equilibrium with higher levels of consumption of both the home good and imports. Exports would be lower due to real appreciation of the exchange rate. The opposite occurs when the elasticity of substitution is greater than one as shown in Table 3.3. Overall, there is an increase in welfare as indicated by the higher level of private consumption $(\mathrm{QH})$ in all cases.

Table 3.3. Some Implications of an Export Boom

\begin{tabular}{cccccccc}
\hline Omega & Sigma & EXR & PD & XD & XE & QM & QH \\
\hline 0.2 & 0.2 & 5850.00 & 1.09 & 1072266.00 & 537746.20 & 537005.30 & 1063891.00 \\
0.5 & 0.5 & 7478.86 & 1.02 & 1063131.00 & 546880.50 & 548260.50 & 1087493.00 \\
0.75 & 1.26 & 8220.28 & .99 & 1039696.00 & 570316.30 & 577137.70 & 1100896.00 \\
2.0 & 2.0 & 8411.19 & .98 & 1016099.00 & 593913.50 & 606213.80 & 1106800.00 \\
5.0 & 5.0 & 8634.83 & .97 & 916265.00 & 693747.00 & 729226.90 & 1123897.00 \\
\hline
\end{tabular}

Source: Computed (QH: Household consumption)

An Increase in the Tariff Rate

The impact of an increase in the tariff rate is revealed by the results presented in Table 3.4. This policy change makes imports more expensive relative to the home good. The demand for imports would decrease as a result. There is also an appreciation of the exchange rate that leads to a decline in exports. This confirms the observation by Devarajan, Lewis and Robinson (1990:644) that an import tariff acts as a tax on exports. 
Table 3.4. Effects of an Increase in the Tariff Rate

\begin{tabular}{cccccccc}
\hline Omega & Sigma & EXR & PD & XD & XE & QM & QH \\
\hline 0.2 & 0.2 & 9235.75 & 0.93 & 1040509.00 & 569503.10 & 459180.30 & 1037550.00 \\
0.5 & 0.5 & 9235.77 & 0.93 & 1041167.00 & 568845.20 & 458504.80 & 1037525.00 \\
0.75 & 1.26 & 9225.12 & 0.93 & 1042175.00 & 567837.00 & 457469.50 & 1037367.00 \\
2.0 & 2.0 & 9235.85 & 0.93 & 1044449.00 & 565562.50 & 455134.10 & 1037396.00 \\
5.0 & 5.0 & 9236.03 & 0.93 & 1050980.00 & 559032.00 & 448428.40 & 1037140.00 \\
\hline
\end{tabular}

Source: Computed

Finally, we note from Table 3.4 that private consumption is uniformly lower than in the base case. This may be due to the fact that none of the tariff revenue is transferred to the consumer who is now facing a higher domestic price for imports with lower income.

\section{Conclusion}

This paper illustrates how to implement numerically a general equilibrium model in EViews. For concreteness and simplicity, we focus on two versions of the generalized Salter-Swan model of a small open economy. The current version of EViews offers a set of tools for building and solving simulation models in general. The same tools make it possible to conduct policy analysis within a general equilibrium framework.

The implementation is presented in four steps. The first shows how to use the matrix and table objects to set up the SAM containing baseline data. The set up is made easier by the possibility of using the "FOR LOOP" controlled by a string variable in order to define and place both column-accounts in the matrix, and corresponding labels in the associated table. The second step concerns model specification, which involves a declaration statement and a series of statements based on the APPEND command. The number of equations entering the model depends on the number of endogenous variables as determined by closure. Unlike a software such as GAMS, EViews can solve only square systems where the number of independent equations is equal to the number of 
endogenous variables. It is important to remember that EViews will treat the first variable encountered in the specification of an equation as the endogenous variable for that equation.

The third step involves calibration and initialization of model variables. All variables can be declared at once using the FOR LOOP controlled by a string variable. Most variables are initialized on the basis of values contained in the SAM. We find it more convenient to set up the calibration process as a separate model whereby structural values of the parameters are computed as a function of observed values of relevant variables. The fact that EViews solves the model for each observation in the workfile means that sensitivity analysis can be built in and performed with a single SOLVE statement. The final step performs simulations starting with the baseline solution. The SCENARIO procedure is a very useful tool in this context as it allows one to keep in the same workfile solution values associated with different assumptions about some exogenous variables. The empirical examples studied in this paper, based on artificial data and a macroeconomic SAM for Indonesia in 2002, replicate the welfare and structural effects of shocks and policies as predicted by the underlying conceptual framework. They also reveal the key role played by structural parameters such as the elasticity of transformation and that of substitution in determining the extent of structural adjustment to shocks and the relevance of the policy response. 


\section{Annex : Computer Code for the Extended Model}

'INDOGSS02.PRG Illustrates how to set up a CGE model based on an aggregate social accounting matrix for Indonesia in billions of 2002 rupiahs (Data Source: LDB on Line World Bank). The analytical structure of the model originates from Devarajan Shantayanan, Lewis Jeffrey D. and Robinson Sherman. 1990. Policy Lessons from Trade-Focused, Two-Sector Models. Journal of Policy Modeling 12(4):625-657.

'B. Essama-Nssah, PRMPR, The World Bank Group, September 14, 2003

WORKFILE INDOGSS02 U 5

'==========Set Up the Social Accounting Matrix==================================== 'Accounts: 1. ACT Activity; 2. COM Commodity; 3. HHD Household; 4.GOV Government; 5.SVI Capital Account; 6. ROW World; 7. TOT Total

MATRIX $(7,7)$ IDMACSAM 'ID is country Code for Indonesia

'Define the Columns of IDMACSAM

FOR \%AC ACT COM HHD GOV SVI ROW TOT

NEXT

VECTOR(7) V\{\%AC $\}$

'Fill in IDMACSAM's Columns with Base Year Data

$\operatorname{VACT}(3)=1538826$

$\operatorname{VACT}(4)=71186$

$\operatorname{VACT}(7)=@ S U M(V A C T)$

$\operatorname{VCOM}(1)=1040070$

$\operatorname{VCOM}(4)=12005$

$\operatorname{VCOM}(6)=447626$

$\operatorname{VCOM}(7)=@ S U M(\operatorname{VCOM})$

$\mathrm{VHHD}(2)=1042148$

$\mathrm{VHHD}(4)=110845$

$\mathrm{VHHD}(5)=405079$

$\mathrm{VHHD}(7)=@ S U M(V H H D)$

$\operatorname{VGOV}(2)=132219$

$\operatorname{VGOV}(5)=61817$

$\operatorname{VGOV}(7)=@ S U M(V G O V)$

$\operatorname{VSVI}(2)=325334$

VSVI(7)=@SUM(VSVI)

$\operatorname{VROW}(1)=569942$

$\operatorname{VROW}(3)=19246$

$\operatorname{VROW}(5)=-141562$

VROW $(7)=@ S U M(V R O W)$

'Load Vectors in IDMACSAM

!COL=1

FOR \%AC ACT COM HHD GOV SVI ROW

COLPLACE(IDMACSAM,V\{\%AC $\}, ! C O L)$

DELETE $\vee\{\% A C\}$ 


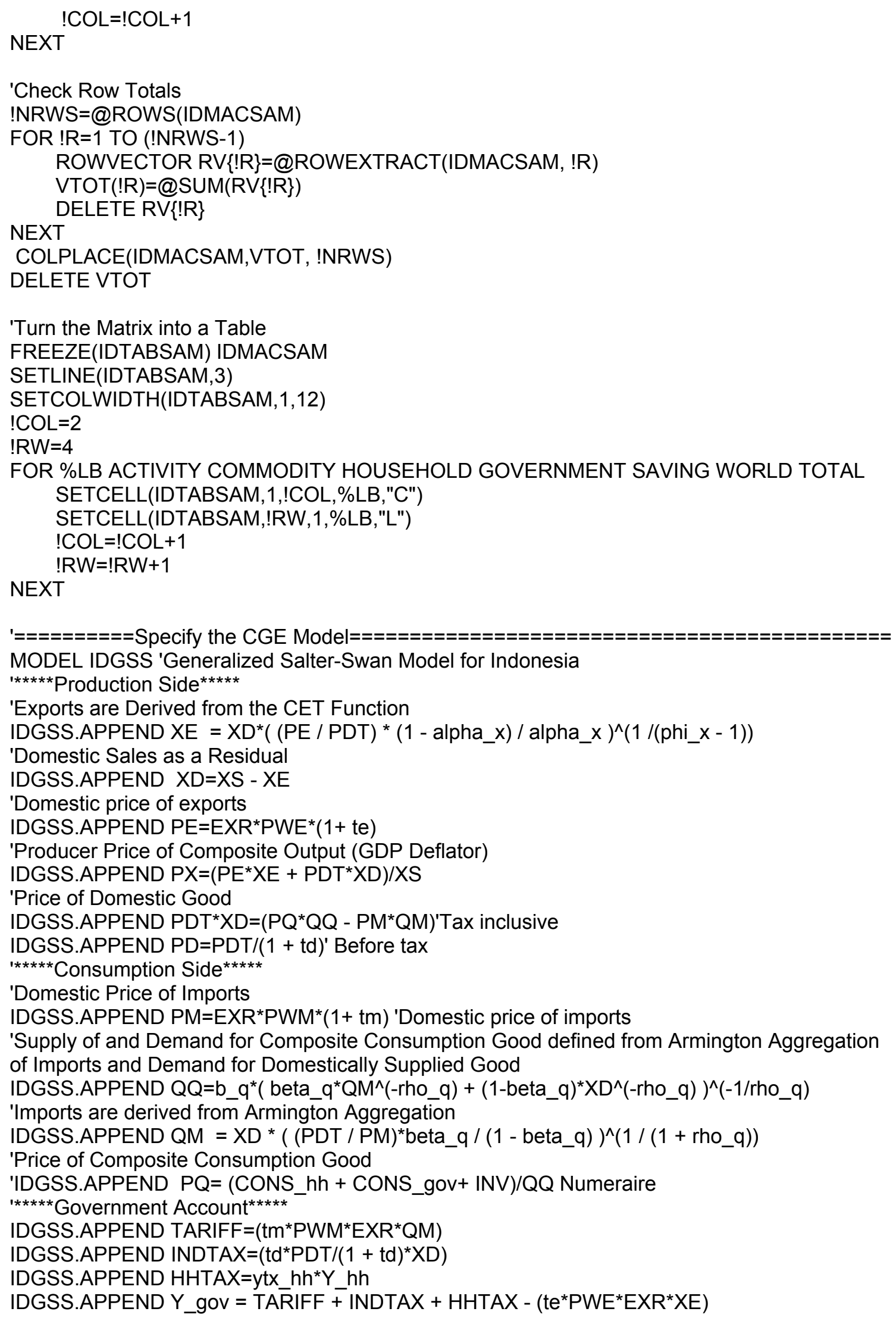




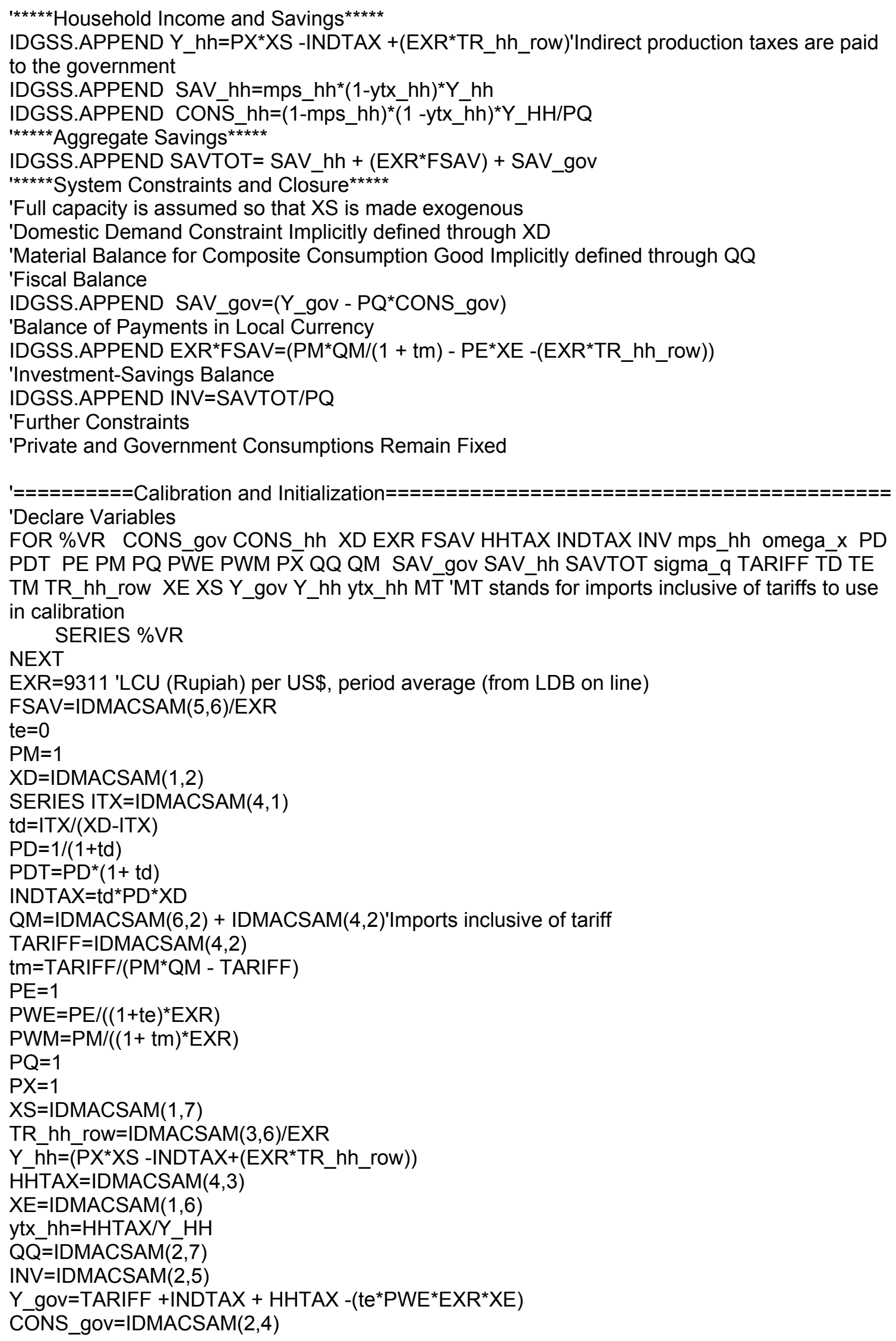


SAV_gov=IDMACSAM $(5,4)$

SAV_hh=IDMACSAM $(5,3)$

mps_hh $=S A V \_h h /\left(\left(1-y t x \_h h\right)^{*} Y \_h h\right)$

CONS_hh $=\left(1-m p s \_h h\right)^{*}\left(1-y t x \_h h\right)^{*} Y \_h h / P Q$

SAVTOT $=S A V \_h h+S A V \_g o v+\left(E X R^{\bar{*}} F S A V\right)$

MODEL CALIBER

omega_x.fill $0.2,0.5,0.75,2,5$ 'Different values of export transformation elasticity for sensitivity analyis

sigma_q.fill $0.2,0.5,1.26,2,5$ 'Different values of trade substitution elasticity;

CALIBER.APPEND rho_q $=(1 /$ sigma_q $)-1$

CALIBER.APPEND phi $\mathrm{x}=(1 /$ omega $\mathrm{x})+1$

CALIBER.APPEND alpha_x $=1 /\left((\mathrm{PDT} / \mathrm{PE})^{*}(\mathrm{XE} / \mathrm{XD})^{\wedge}(1 /\right.$ omega_ $\left.\mathrm{x})+1\right)$ 'Share for the CET

function

CALIBER.APPEND a_x $=X S /\left(\text { alpha_ } x^{*} X E^{\wedge} p h i \_x+(1-\text { alpha_ } x)^{\star} X D^{\wedge} p h i \_x\right)^{\wedge}\left(1 / p h i \_x\right)$ 'Scale

factor for the CET function

CALIBER.APPEND beta_q $=\left((\text { PM/PDT })^{\star}(\mathrm{QM} / \mathrm{XD})^{\wedge}(1+\right.$ rho_q $\left.)\right) /(1+$

$(P M / P D T)^{\star}(Q M / X D)^{\wedge}(1 /$ sigma_q) ) 'Share factor for the CES function

CALIBER.APPEND b_q $=\mathrm{QQ} /\left(\text { beta_q }{ }^{*} Q M^{\wedge}\left(-r h o \_q\right)+(1-\text { beta_q) })^{\star} X D^{\wedge}\left(-r h o \_q\right)\right)^{\wedge}(-1 /$ rho_q)

'Scale factor for the CES function

CALIBER.SCENARIO ACTUALS

CALIBER.SOLVE $(s=d, d=s, 0=n)$

CALIBER.MAKEGROUP CALGRP @ENDOG

FREEZE(CALTAB) CALGRP

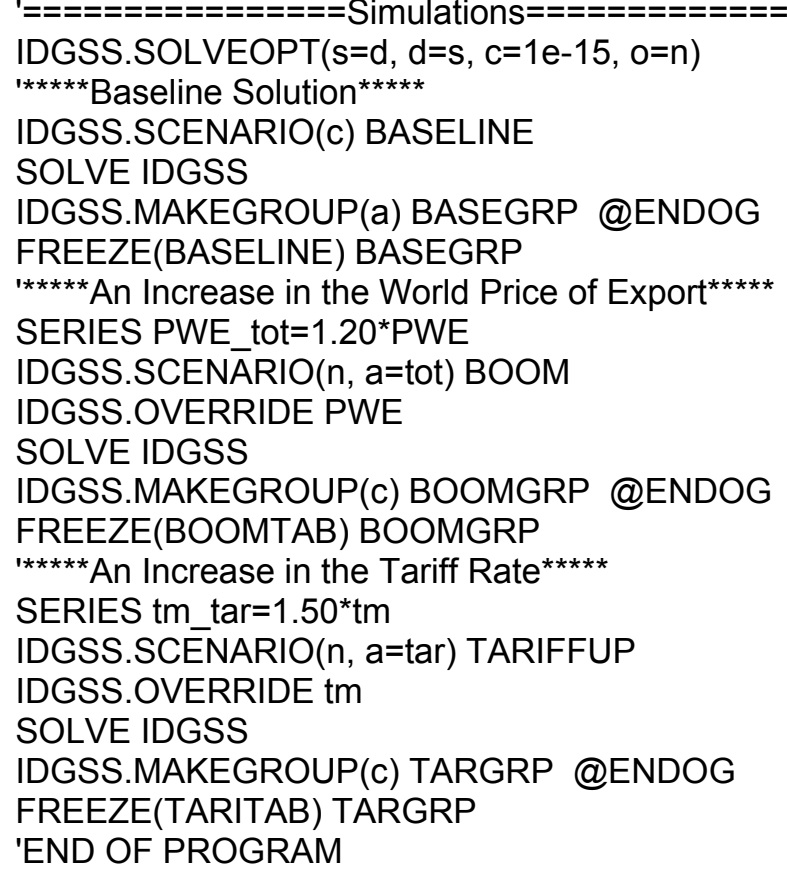




\section{References}

Agénor, Pierre-Richard. 2000. The Economics of Adjustment and Growth. San Diego (California): Academic Press.

Armington, Paul S. 1969. A Theory of Demand for Products Distinguished by Place of Production. IMF Staff Papers Vol. 16, pp. 159 - 176. Washington, D.C.: The international Monetary Fund.

Bandara, Jayatilleke S. 1991. Computable Gneral Equilibrium Models for Development Policy Analysis. Journal of Economic Surveys, Vol. 5, No.1 : 3-69.

Benjamin, Nancy C. and Devarajan Shantayanan. 1985. Oil Revenues and Economic Policy in Cameroon: Results from a Computable General Equilibrium Model. World Bank Staff Working Papers No. 745. Washington, D.C.: The World Bank. . and Shantayanan Devarajan and Robert J. Weiner. 1989. The "Dutch" Disease in a Developing Country : Oil reserves in Cameroon. Journal of Development Economics. Vol. 30: 71 - 92.

Decaluwé Bernard, Martens André and Savard Luc. 2001. La politique économique du développement et les modèles d'équilibre général calculable. Montréal : Les Presses de l’Université de Montréal.

de Melo, Jaime. 1988a. SAM-Based Models : An Introduction. Journal of Policy Modeling vo. 10, No.3: $321-325$

de Melo, Jaime. 1988b. Computable General Equilibrium Models for Trade Policy Analysis in Developing Countries : A Survey. Journal of Policy Modeling vol. 10, No.4 : 469 $-503$.

de Melo, Jaime and Sherman Robinson. 1989. Product Differentiation and the Treatment of Foreign Trade in Computable General Equilibrium Models of Small Economies. Journal of International Economics vol. $27: 47$-67.

Dervis, Kemal, Jaime de Melo and Sherman Robinson. 1982. General Equilibrium Models for Development Policy. Washington, D.C.: The World Bank.

Devarajan Shantayanan and Robinson Sherman. 2002. The Influence of Computable General Equilibrium Models on Policy. Washington, DC.: International Food Policy Research Institute, Trade and Macroeconomics Division Discussion Paper No. 98 (August). 
Devarajan, Shantayanan, Go Delfin S. and Li Hongyi. 1999. Quantifying the Fiscal Effects of Trade Reform: A General Equilibrium Model Estimated for 60 Countries. World Bank Policy Research Working Paper No. 2162. Washington, D.C.: The World Bank.

Devarajan Shantayanan, Go Delfin S., Lewis Jeffrey D., Robinson Sherman and Sinko Pekka. 1997. Simple General Equilibrium Modeling. In Joseph François and Kenneth Reinert (eds), “Applied Methods for Trade Policy Analysis: A Handbook”. Cambridge: Cambridge University Press.

Devarajan, Shantayanan, Jeffrey D. Lewis, and Sherman Robinson. 1993. External Shocks, Purchasing Parity Power and The Equilibrium Real Exchange Rate. World Bank Economic Review 7:45-63.

Devarajan, Shantayanan, Jeffrey D. Lewis, and Sherman Robinson. 1990. Policy Lessons From Two-sector Models. Journal of Policy Modeling 12 (4): 625-657.

Devarajan, Shantayanan and Jeffrey D. Lewis. 1989. Structural Adjustment and Economic Reform in Indonesia : Model-based Policies vs Rules-Of-Thumb. Cambridge, M.A.: Harvard University.

Devarajan, Shantayanan and Jaime de Melo. 1987. Adjustment with a Fixed Exchange Rate: Cameroon, Côte-d'Ivoire, and Sénégal. The World Bank Economic Review, vol. No.3 : 447 -487. Washington, D.C.: The World Bank.

Dinwiddy, C.L. and F.J. Teal. 1988. The Two-Sector General Equilibrium Model: A new Approach. Oxford: Philip Allan.

Dixit A. K. 1996. The Making of Economic Policy: A Transation-Cost Politics Perspective. Cambridge (Massachusetts): MIT Press.

Dorosh, Paul A. and B. Essama-Nssah, and Samaba-Mamadou, O. 1996. Terms of Trade and the Real Exchange Rate in the CFA Zone: Implications for Income Distribution in Niger. In David E. Sahn (ed.) Economic Reform in Africa. Oxford: OxfordClarendon.

Dorosh, Paul A. and B. Essama-Nssah. 1993. External Shocks, Policy Reform and Income Distribution in Niger. Washington, D.C.: Cornell University Food and Nutrition Policy Program. Working Paper No.40. 
Dorosh, Paul A. and B. Essama Nssah. 1991. A Social Accounting Matrix for Niger: Methodology and Results. Washington, D.C.: Cornell University Food and Nutrition Policy Program, Working paper No.18.

Essama-Nssah, B. 1991a. Destabilization and Adjustment in a Small Open Developing Economy: A Framework for Analysis Washington, D.C.: Cornell University Food and Nutrition Policy Program (December).

, 1991b. Introduction au Système de Modélisation GAMS. Washington,

D.C.: Cornell University Food and Nutrition Policy Program.

King, Benjamin B. 1985. What is a SAM ? in Graham Pyatt and Jeffrey I. Round, eds. Social Accounting Matrices : a Basis for Planning. Washington, D.C.: The World Bank.

Löfgren Hans, Harris Rebecca Lee, and Robinson Sherman with assistance from Thomas Marcelle and El-Said Moataz. 2002. A Standard Computable General Equilibrium (CGE) Model in GAMS. Washington, D.C. : International Food Policy Research Institute (IFPRI).

Quantitative Micro Software (QMS). 2000. Eviews 4.0 User's Guide. Irvine, CA: QMS.

Quantitative Micro Software (QMS). 2000. Eviews 4.0 Command and Programming Reference. Irvine, CA: QMS.

Quantitative Micro Software (QMS). 2002. Eviews 4.1 Help. Irvine, CA: QMS.

Quade, E.S. 1982. Analysis for Public Decisions. New York: North-Holland.

Rattso, John. 1982. Different Macroclosures of the Original Johansen Model and their Impact on Policy Evaluation. Journal of Policy Modeling vol. 4, No.1 : 85-97.

Roberts Barbara M. 1994. Calibration Procedure and the Robustness of CGE Models : Simulations with a Model for Poland. Economics of Planning, 27 : 189-210.

Robinson, Sherman. 2003. Macro Models and Multipliers: Leontief, Stone and CGE Models. Washington, D.C.: International Food Policy Research Institute (IFPRI). 1989. Multisectoral Models, in Hollis Chenery and T.N. Srimivasan, eds., Handbook of Development Economics Vol. 2. Amsterdam: North-Holland. , Yunez_Naude Antonio, Hinojosa-Ojeda Raul, Lewis Jeffrey D. And Devarajan Shantayanan. 1999. From Stylized to Applied Models: Building 
Multisector CGE Models for Policy Analysis. Journal of Economics and Finance 10: 5-38.

Round, Jeffrey I. 2003. Constructing SAMs for Development policy Analysis. Lessons Learned and Challenges Ahead. Economic Systems Research, Vol. 15, No.2: 161183 (June).

Sadoulet Elisabeth and de Janvry Alain. 1995. Quantitative Development Policy Analysis. Baltimore: The Johns Hopkins University Press.

Salter, W.E.G. 1959. Internal and External Balance : The Role of Price and Expenditure Effects. The Economic Record vol. XXXV. No. $71: 226$ - 238.

Swan, T. 1960. Economic Control in a Dependent Economy. Economic Record XXXVI: 51-66. 